\title{
Health promotion interventions for increasing stroke awareness in ethnic minorities: a systematic review of the literature
}

\author{
Paolo Gardois ${ }^{1 * \dagger}$, Andrew Booth ${ }^{1 \dagger}$, Elizabeth Goyder ${ }^{1 \dagger}$ and Tony Ryan ${ }^{2+}$
}

\begin{abstract}
Background: Stroke places a significant burden to all affected individuals, but it is perhaps more significant amongst members of black, minority and ethnic communities, who may experience poorer awareness of stroke symptoms than the general population. Recently, several initiatives tried to improve public awareness that symptoms of stroke need to be treated as a medical emergency. However, ethnic communities present cultural barriers, requiring tailored health promotion interventions, whose effectiveness remains uncertain. Our systematic review aimed to identify relevant published evidence, synthesize the main study components and identify evidence of the effectiveness of the interventions.

Methods: MEDLINE, EMBASE, CINAHL, and Psyclnfo were searched for journal articles on health promotion interventions for increasing stroke awareness in ethnic minorities, published in English between 1995 and 2012. Search results were collaboratively assessed by the authors; included studies were analysed to identify their main characteristics, and a thematic analysis of their content was conducted. No meta-analysis was performed, due to the heterogeneity of results.
\end{abstract}

Results: Eighteen studies were included, reporting 15 interventions conducted in the US, for African-Americans or Hispanics; populations sizes differed between interventions. Interventions were mostly carried out in community settings with different educational techniques, focussing on experiential methods. Health professionals usually organized the programs, delivered by nurses, other health professionals or volunteers.

The few theory-based interventions focussed on individual-level behavioural change. Practical cultural adaptation strategies were not linked to specific theoretical frameworks. Interventions widely differed as for target populations, settings, delivery methods, contents and professional roles involved. All study designs were quantitative, and the emerging evidence of effectiveness was inconclusive.

Such interventions operate in very complex scenarios, and several variables may influence their effectiveness. Therefore, qualitative or mixed-methods study designs may shed light on barriers and facilitators, experiential education strategies and community involvement.

Network- and community-level theories may help improving design and evaluation of interventions.

Conclusions: Eleven case reports and four RCTs provide evidence about stroke awareness interventions organized in the US. The studies provide only partial and inconclusive evidence about the effectiveness of the interventions. Hence, further research is needed on different countries and ethnic minorities.

\footnotetext{
*Correspondence: pgardois@gmail.com

'Equal contributors

'School of Health and Related Research, University of Sheffield, Regent Court, 30 Regent Street, Sheffield S1 4DA, UK

Full list of author information is available at the end of the article
} 


\section{Background}

The need to increase stroke awareness in black, minority and ethnic communities (BMEs) is a difficult, but vital challenge, required to save lives and reduce inequalities.

Stroke places a significant burden on BME community members. The second highest cause of death in the world [1], stroke in 2004 had a worldwide prevalence of 30.7 million cases, with 9 million new cases every year [2]. A significant proportion of patients die from stroke [3], and survivors often experience disability or impairment for US data, see $[4,5]$. Consequently, health system costs resulting from stroke-related deaths and disabilities are high, between 2 and $4 \%$ of total expenditure [3,6,7]. This significant financial burden is likely to increase in the future since the majority of strokes affects the elderly [7]. Studies from the U.S. $[8,9]$ and the UK $[10,11]$ suggest that ethnic minorities experience higher stroke risk and incidence and worse outcomes in comparison to the general population, due to hereditary, environmental, social and health-system factors. Moreover, ethnic minorities experience increased risk of pre-hospital delays, and show lower stroke awareness than the general population.

Current evidence based management of stroke involves rtPA thrombolysis within three hours from onset [12]. It is thus imperative that symptoms are recognized early to allow prompt admission to the nearest stroke unit. Nonetheless, very few eligible patients receive the recommended treatment $[13,14]$, mainly because of delayed hospital admission due to pre-hospital delays, i.e. delays occurring from the onset of symptoms to admission $[15,16]$. Two studies suggests that belonging to a BME community increases the risk of significant prehospital delays $[16,17]$.

In addition to acting on preventable risk factors [18], the strategy of increasing stroke awareness has often been employed to reduce pre-hospital delays, both in the general population and in BME communities. A recent review showed that awareness of symptoms of stroke is low in the general population, and tends to be poorer in ethnic communities [19]. Consequently, stroke awareness improvement is part of national stroke strategies in different countries [20-23]. Furthermore, a recent review [16] shows that initiatives to improve awareness that symptoms of stroke need to be treated as a medical emergency have recently been undertaken in several countries. Such initiatives used different channels and strategies, such as mass media advertisements, community involvement and health education techniques. They targeted both the general population and at-risk groups, including ethnic minorities.

However, the evidence of effectiveness of the initiatives for stroke awareness improvement is inconclusive, especially for interventions targeting BME populations. Awareness of stroke symptoms does not automatically translate into the ability to recognize such stroke symptoms in a patient [24]. In particular, no linear relationship emerges between the level of stroke awareness in a community, the behavioural intent to call emergency medical services (EMS) when witnessing a stroke, and the reduction of pre-hospital delays [25-27]. Deciding to call the EMS when witnessing a stroke resembles a collective, network-mediated, community-based decisionmaking process [28-30]. Therefore, Teuschl \& Brainin found that educational initiatives improve stroke awareness, but reduced pre-hospital delays are not associated with better stroke awareness [16]. Ethnic communities include a high concentration of at-risk individuals, and present cultural barriers to the uptake of stroke awareness messages, requiring community-based and culturally tailored health promotion interventions [31,32]. For example, in the UK the effect of mass media campaigns such as F.A.S.T. ${ }^{\text {a }}$ [33] on BME community members seems to be limited [34,35]. Thisprompted the UK National Audit Office to state that "The Department [of Health] (...) should consider particularly how to engage with groups at higher risk of stroke, such as people of Afro-Caribbean and South Asian ethnicity" [36]. Finally, recent contributions have tried to define the cultural appropriateness of interventions and the main principles for conducting research in ethnicity and health [37-39].

It is therefore critical to understand which health promotion interventions have been carried out to increase awareness of stroke symptoms and adequate response in BME communities, and whether there is evidence to demonstrate their effectiveness. Consequently, we decided to review the literature to establish the main characteristics of health promotion interventions directed towards increasing awareness of stroke symptoms and appropriate response (i.e., calling EMS) in BME communities. Additionally, we assessed the evidence of their effectiveness.

\section{Methods}

To answer our research questions, we undertook a systematic review of the literature. We aimed to retrieve all studies describing health promotion interventions designed for increasing awareness of stroke symptoms and appropriate response (i.e., calling EMS) in BME communities. We also decided to map the main study components and to identify any evidence of effectiveness of the described interventions. This section describes the search strategy, inclusion and exclusion criteria for identified articles, the process of article selection and the process of data analysis and synthesis.

Our review had the following objectives:

identifying relevant published evidence; selecting studies according to rigorous inclusion and exclusion criteria; 
synthesizing the main components of included studies; identifying evidence of the effectiveness of the described interventions, if any.

The PRISMA checklist [40] was used as a guide to report the results of the review.

\section{Search, screening and selection strategy}

Firstly, we conducted a systematic search on four health sciences databases: Pubmed MEDLINE, EMBASE, CINAHL, and PsycInfo. The searches were performed on 17/01/2012, with the search string described in Table 1.

The string matched our inclusion and exclusion criteria (see below), and it was agreed upon by all authors, following pilot searches that combined different permutations of terms. The second and third steps in the search strategy were directed at identifying In-Process articles included in the database in the six months prior to the search, which would be lost if using only the first step in the strategy. The first author performed the same search, with the necessary adaptations, in the other three databases.

\section{Inclusion and exclusion criteria}

Only studies describing one or more health promotion interventions aimed at increasing awareness of stroke symptoms, warning signs and appropriate response (i.e., calling EMS) in BME communities were eligible for inclusion. We defined BME communities as any ethnic minority community in any country. Consequently, any intervention whose target audience was composed of at least 50\% BME community members was eligible for inclusion. We included interventions if they targeted either the general population of BME communities, or specific subcategories, e.g. students, parents, the elderly or stroke survivors. However, we excluded articles describing health interventions only aimed at health professionals or lay health workers, including health champions (i.e. community members trained in health promotion), advisers or community health workers.

We also included studies if stroke awareness was not the sole aim of the reported interventions. For example, some articles related to interventions concerning stroke risk factors in addition to stroke awareness, while others concerned knowledge of cardiovascular diseases or

Table 1 Search strings used in the Pubmed database

\begin{tabular}{ll}
\hline Steps & Search string \\
\hline 1 & ("Stroke"[Mesh] AND (knowledge OR ("warning sign" OR \\
& "warning signs") OR recognition OR awareness) Limits: \\
& Humans, English, Publication Date from 1996) \\
2 & $\begin{array}{l}\text { (stroke AND (knowledge OR ("warning sign" OR } \\
\text { "warning signs") OR recognition OR awareness) } \\
\end{array}$ \\
& AND ("2011/07/15"[Date - Entrez] : "3000" [Date - Entrez])) \\
& 1 OR 2 \\
\hline
\end{tabular}

diabetes alongside stroke awareness itself. We excluded studies identifying barriers, facilitators, or specific attitudes and needs of potential targets of stroke awareness interventions, and studies identifying theoretical issues not related to data emerging from health promotion interventions.

Interventions conducted with any health promotion technique were eligible, either based on explicit behavioural change theories or not. We did not exclude any article because of the study design. However, we only included refereed articles since they usually represent the most updated and highest-quality literature on health promotion, in comparison to other scientific contributions (e.g.: books, conference proceedings, dissertations, etc.). We only included articles in English for practical reasons relating to non-availability of translation services. In addition, we considered eligible for inclusion only articles published from 1996, since the first trial showing effectiveness and safety of rtPA for stroke treatment if administered within three hours of onset of symptoms was published in December 1995 [41]. It is therefore assumed that this trial would only have had an impact on health promotion interventions after 1995.

\section{Data analysis and synthesis}

A first scan reading of the included articles allowed us to produce a first group of categories used to summarize the content of the articles. We then developed a sheet [42], using Microsoft Excel 2010. The sheet was refined while reading the full text of the articles and through discussion between authors. In its final form, it included the columns now showed in Tables 2, 3, 4 and 5.

Given the heterogeneity of the included study designs, a quantitative meta-analysis of results would not be possible. Data emerging from the analysis of the identified variables have therefore been aggregated and described in terms of the three identified elements of the research question (population, intervention and outcomes/study design). In addition, to obtain insights from the data, the first author also read in depth the selected articles, and performed a thematic analysis of the main emerging topics [43]. Such topics were either used to integrate and clarify the meaning of variables included in the tables, or to explore further dimensions of the interventions.

\section{Search results}

The PRISMA 2009 flow diagram reported in Figure 1 [40] depicts the process of selection and identification of articles.

The searches in the four databases yielded 7549 references, included in a database using the reference management software Endnote X2 by Thomson Reuters. Thereafter, automatic deduplication of results was performed, followed by a manual check of all remaining 
Table 2 Characteristics of populations targeted by the interventions

\begin{tabular}{|c|c|c|c|c|c|}
\hline ID & Study & Target ethnic groups & Intervention level & Population & Population size \\
\hline 1 & Boden-Albala 2010 [44] & Hispanics; African Americans & Groups & Survivors (stroke and TIA) & Large: 736 \\
\hline 2 & Chan 2008 [45] & African Americans & Individuals & General population & Medium: 1981 \\
\hline 3 & Covington 2010 [46] & African Americans & Groups & General population & Small: 16 \\
\hline 4 & Dromerick 2011 [47] & African Americans & Individuals & Survivors (stroke and TIA) & Medium: 250 \\
\hline 5 & $\begin{array}{l}\text { Duraski } 2003 \text { [48]; } \\
\text { Duraski } 2006 \text { [49] }\end{array}$ & Hispanics & Groups & General population & Medium: 177 \\
\hline 6 & Duraski 2007 [50] & Hispanics & Groups & Children and young adults (aged 9-26) & Small: 32 \\
\hline 7 & Frank 2008 [51] & African Americans & Groups & Parishioners of African-American churches & Medium: 120 \\
\hline 8 & Kalenderian 2009 [53] & African Americans; Hispanics & Groups & Individuals taking part in church activities & Large: > 1500 \\
\hline 9 & Kleindorfer 2008 [54] & African Americans & Individuals & Women & Medium: 383 \\
\hline 10 & Miller 2003 [55] & African Americans & Individuals & Patients at risk for stroke & Small: 60 \\
\hline 11 & $\begin{array}{l}\text { Morgenstern } 2007 \text { [56]; } \\
\text { Gonzales } 2007 \text { [52]; } \\
\text { Mullen Conley } 2010 \text { [29] }\end{array}$ & Mexican Americans & Groups & Middle school students and their parents & Large: 706 \\
\hline 12 & Villablanca 2009 [57] & African Americans; Hispanics & Groups & Women aged $>40$ years & Large: 1052 \\
\hline 13 & Williams 2008 [58] & Hispanics; African Americans & Groups & Students aged 9-11 & Large: 582 \\
\hline 14 & Williams 2012 [59] & African Americans; Hispanics & Individuals & Parents of primary school children & Medium: 101 \\
\hline 15 & Williamson 2009 [60] & African Americans & Groups & Members of an Afro-American church & Medium: 325 \\
\hline
\end{tabular}

references. We identified 1812 items as duplicates, while the remaining 5737 articles represented the initial dataset on which the selection was performed. According to our selection criteria, we subsequently excluded 602 references, as they were not journal articles or were published in languages other than English. We therefore conducted the screening on 5135 references. In this phase, the first author screened the title of each reference to verify if it matched the inclusion criteria. Cases of uncertainty were resolved by reading the abstract, if

Table 3 Outcomes and study design of selected studies

\begin{tabular}{|c|c|c|c|c|}
\hline ID & Study & Study design & Evaluation method & Reported effectiveness $^{a}$ \\
\hline 1 & Boden Albala 2010 [44] & $\begin{array}{l}\text { Randomized controlled trial } \\
(\mathrm{RCT})\end{array}$ & $\begin{array}{l}\text { Article reports only on protocol } \\
\text { and baseline }\end{array}$ & $\begin{array}{l}\text { Article reports only on protocol } \\
\text { and baseline }\end{array}$ \\
\hline 2 & Chan 2008 [45] & $\mathrm{RCT}$ & Pre-post test & Yes \\
\hline 3 & Covington $2010[46]$ & Case study & None & Not applicable \\
\hline 4 & Dromerick 2011 [47] & $\mathrm{RCT}$ & $\begin{array}{l}\text { Article reports only on protocol } \\
\text { and baseline }\end{array}$ & $\begin{array}{l}\text { Article reports only on protocol } \\
\text { and baseline }\end{array}$ \\
\hline 5 & Duraski 2006 [49]; Duraski 2003 [48] & Case study & Pre-post test & Yes \\
\hline 6 & Duraski 2007 [50] & Case study & None & Not applicable \\
\hline 7 & Frank 2008 [51] & Case study & Pre-post test & No \\
\hline 8 & Kalenderian 2009 [53] & Case study & None & Not applicable \\
\hline 9 & Kleindorfer 2008 [54] & Case study & Pre-post test & Yes \\
\hline 10 & Miller 2003 [55] & $\begin{array}{l}\text { Case study (repeated measures } \\
\text { design with } 3 \text { groups) }\end{array}$ & Pre-post test & $\begin{array}{l}\text { No effectiveness for treatment seeking } \\
\text { behaviour (call EMS); unknown } \\
\text { effectiveness for knowledge of stroke } \\
\text { symptoms }\end{array}$ \\
\hline 11 & $\begin{array}{l}\text { Morgenstern } 2007 \text { [56]; Gonzales } 2007 \\
\text { [52]; Mullen Conley } 2010 \text { [29] }\end{array}$ & $\mathrm{RCT}$ & Pre-post test & Yes for children; unknown for parents \\
\hline 12 & Villablanca 2009 [57] & Case study & $\begin{array}{l}\text { None (only for outcomes other } \\
\text { than stroke symptoms) }\end{array}$ & Not applicable \\
\hline 13 & Williams 2008 [58] & Case study & Pre-post test & Yes \\
\hline 14 & Williams 2012 [59] & Case study & Pre-post test & Yes \\
\hline 15 & Williamson 2009 [60] & Case study & None & Not applicable \\
\hline
\end{tabular}

${ }^{a}$ Effectiveness of an intervention refers to its ability to improve the knowledge of stroke symptoms and the intention to call 999 in target populations. 
Table 4 Intervention type, focus, duration and setting

\begin{tabular}{|c|c|c|c|c|c|}
\hline ID & Study & Intervention type & Focus & Duration of intervention & Setting \\
\hline 1 & Boden-Albala 2010 [44] & - Two sessions about stroke education & Awareness & $\begin{array}{l}2 \text { brief sessions within } \\
3 \text { weeks of stroke/TIA } \\
\text { onset }\end{array}$ & Hospital or home \\
\hline 2 & Chan 2008 [45] & - Stroke education program (video) & Awareness & 12 minutes & Emergency department \\
\hline \multirow[t]{3}{*}{3} & \multirow[t]{3}{*}{ Covington 2010 [46] } & - PowerPoint presentation & \multirow[t]{3}{*}{ Equal focus } & \multirow[t]{3}{*}{ Single, brief session } & - Churches \\
\hline & & - Educational materials to take home & & & - Group homes \\
\hline & & - Blood pressure screening and referral & & & $\begin{array}{l}\text { - Community centers, } \\
\text { and community } \\
\text { organizations" }\end{array}$ \\
\hline 4 & Dromerick 2011 [47] & - Stroke navigators visiting patients & Equal focus & $\begin{array}{l}\text { Advice sessions over } \\
\text { one year }\end{array}$ & Home \\
\hline \multirow[t]{3}{*}{5} & \multirow{3}{*}{$\begin{array}{l}\text { Duraski } 2006 \text { [49]; } \\
\text { Duraski } 2003 \text { [48] }\end{array}$} & - Short slide presentation & \multirow[t]{3}{*}{ Equal focus } & \multirow[t]{3}{*}{1 to 2 hours } & \multirow{3}{*}{$\begin{array}{l}\text { Community centres } \\
\text { and community } \\
\text { organizations }\end{array}$} \\
\hline & & - Stroke risk assessment screening & & & \\
\hline & & - Advice/discussion. & & & \\
\hline \multirow[t]{3}{*}{6} & \multirow[t]{3}{*}{ Duraski 2007 [50] } & - Focus group session & \multirow[t]{3}{*}{ Awareness } & \multirow[t]{3}{*}{30 to 60 minutes } & \multirow[t]{3}{*}{ Unknown } \\
\hline & & - Slide presentation & & & \\
\hline & & - Interactive questions/answers & & & \\
\hline \multirow[t]{3}{*}{7} & \multirow[t]{3}{*}{ Frank 2008 [51] } & $\begin{array}{l}\text { - Cardiovascular diseases and stroke } \\
\text { education sessions }\end{array}$ & \multirow[t]{3}{*}{$\begin{array}{l}\text { Prevention/ } \\
\text { risk factors }\end{array}$} & \multirow[t]{3}{*}{$\begin{array}{l}\text { About } 2 \text { hours for } \\
\text { each intervention }\end{array}$} & \multirow[t]{3}{*}{$\begin{array}{l}\text { African-American } \\
\text { churches }\end{array}$} \\
\hline & & - Screening & & & \\
\hline & & $\begin{array}{l}\text { - Integration with Bible study, individual } \\
\text { counselling, healthy food }\end{array}$ & & & \\
\hline \multirow[t]{2}{*}{8} & \multirow[t]{2}{*}{ Kalenderian 2009 [53] } & $\begin{array}{l}\text { - Educational sessions, distribution of } \\
\text { educational package to "ambassadors" }\end{array}$ & \multirow[t]{2}{*}{$\begin{array}{l}\text { Prevention/ } \\
\text { risk factors }\end{array}$} & \multirow[t]{2}{*}{$\begin{array}{l}\text { Various, depending on } \\
\text { specific interventions }\end{array}$} & \multirow[t]{2}{*}{$\begin{array}{l}\text { Faith-based institutions, } \\
\text { churches }\end{array}$} \\
\hline & & $\begin{array}{l}\text { - Educational activities by ambassadors } \\
\text { in churches, e.g. by brochures, videos, posters. }\end{array}$ & & & \\
\hline \multirow[t]{2}{*}{9} & \multirow[t]{2}{*}{ Kleindorfer 2008 [54] } & - Trained beauticians educated their customers & \multirow[t]{2}{*}{ Awareness } & \multirow{2}{*}{$\begin{array}{l}\text { A session at the beauty } \\
\text { salon }\end{array}$} & \multirow[t]{2}{*}{ Beauty salons } \\
\hline & & - Distribution of stroke-related study packets & & & \\
\hline 10 & Miller 2003 [55] & $\begin{array}{l}\text { - Education about knowledge of stroke } \\
\text { symptoms and modifiable stroke risk factors. }\end{array}$ & Equal focus & $\begin{array}{l}\text { 1-hour initial educational } \\
\text { intervention:15' follow-up }\end{array}$ & $\begin{array}{l}\text { Medical practice (some } \\
\text { follow-ups at home). }\end{array}$ \\
\hline \multirow[t]{2}{*}{11} & \multirow[t]{2}{*}{$\begin{array}{l}\text { Morgenstern } 2007 \text { [56]; } \\
\text { Gonzales } 2007 \text { [52]; Mullen } \\
\text { Conley } 2010 \text { [29] }\end{array}$} & $\begin{array}{l}\text { - Lessons to children about stroke signs } \\
\text { and symptoms and to improve skills, } \\
\text { self-efficacy and behaviour. }\end{array}$ & Awareness & $\begin{array}{l}\text { - Four } 50 \text {-minute classes } \\
\text { each year for three years }\end{array}$ & School and home \\
\hline & & $\begin{array}{l}\text { - Parents were taught about stroke by } \\
\text { their children as homework assignment }\end{array}$ & & $\begin{array}{l}\text { - homework with parents } \\
\text { at home. }\end{array}$ & \\
\hline 12 & Villablanca 2009 [57] & - Clinical lectures & Prevention/ & 12-14 counselling sessions, & Various faith-based, \\
\hline & & $\begin{array}{l}\text { - Health demonstrations, video } \\
\text { presentations, personal testimonies, } \\
\text { medical screenings }\end{array}$ & & $\begin{array}{l}\text { (only a minority on stroke } \\
\text { awareness) }\end{array}$ & $\begin{array}{l}\text { academic and } \\
\text { non-academic sites }\end{array}$ \\
\hline 13 & Williams 2008 [58] & $\begin{array}{l}\text { - "Culturally and age-appropriate } \\
\text { music and dance to enhance an } \\
\text { interactive didactic curriculum } \\
\text { including the FAST mnemonic" }\end{array}$ & Awareness & $\begin{array}{l}\text { 1-hour sessions over } \\
3 \text { consecutive days }\end{array}$ & School \\
\hline 14 & Williams 2012 [59] & - Stroke communication intervention & Equal focus & Short (not quantified) & Home \\
\hline & & $\begin{array}{l}\text { - Shared completion of stroke-related } \\
\text { homework between children and parents }\end{array}$ & & & \\
\hline 15 & Williamson 2009 [60] & • "Educational session & Prevention/ & Interventions over & A rural African \\
\hline & & $\begin{array}{l}\text { - Health screenings and weight } \\
\text { watchers program }\end{array}$ & risk factors & two years & ch \\
\hline & & - Integration with faith-based activities & & & \\
\hline
\end{tabular}


Table 5 Health professionals, theories and cultural adaptation of interventions

\begin{tabular}{|c|c|c|c|c|}
\hline ID & Study & Administered by & Theories & Cultural adaptation \\
\hline \multirow[t]{7}{*}{1} & \multirow[t]{7}{*}{ Boden-Albala 2010 [44] } & - Two health educators & - Social cognitive theory & $\begin{array}{l}\text { - Bilingual materials with translation by } \\
\text { community health worker }\end{array}$ \\
\hline & & \multirow[t]{6}{*}{ - 1 physician or nurse } & \multirow[t]{6}{*}{ - Motivational interviewing } & - Visuals integrating community places \\
\hline & & & & $\begin{array}{l}\text { - Film footage of community stroke survivors } \\
\text { recalling stroke experiences in their } \\
\text { own language }\end{array}$ \\
\hline & & & & $\begin{array}{l}\text { - Integration and instructions for current } \\
\text { community resources }\end{array}$ \\
\hline & & & & $\begin{array}{l}\text { - Conversations about barriers such as } \\
\text { mistrust of the health care system }\end{array}$ \\
\hline & & & & $\begin{array}{l}\text { - A community committee evaluated cultural } \\
\text { appropriateness of the intervention }\end{array}$ \\
\hline & & & & - Involvement of local stroke support group \\
\hline 2 & Chan 2008 [45] & $\begin{array}{l}\text { - African American actors instructed } \\
\text { by Stroke Association }\end{array}$ & - None & $\begin{array}{l}\text { - Video produced by the American Heart } \\
\text { Association, with African-American actors }\end{array}$ \\
\hline \multirow[t]{2}{*}{3} & \multirow[t]{2}{*}{ Covington 2010 [46] } & \multirow{2}{*}{$\begin{array}{l}\text { - Trained college students acting } \\
\text { as health champions }\end{array}$} & - Social cognitive theory & \multirow{2}{*}{$\begin{array}{l}\text { - Generic mention that the presentations } \\
\text { were "culturally sensitive". }\end{array}$} \\
\hline & & & - Stages of change & \\
\hline \multirow[t]{3}{*}{4} & \multirow[t]{3}{*}{ Dromerick 2011 [47] } & \multirow[t]{3}{*}{ - Lay community health workers } & - Theory of reasoned action & $\begin{array}{l}\text { - Usage of American Heart Association's } \\
\text { tailored educational materials }\end{array}$ \\
\hline & & & - theory of planned behaviour & - Provision of tailored health education \\
\hline & & & - motivational interviewing & \\
\hline \multirow[t]{5}{*}{5} & \multirow[t]{5}{*}{$\begin{array}{l}\text { Duraski } 2006 \text { [49]; } \\
\text { Duraski } 2003 \text { [48] }\end{array}$} & \multirow[t]{5}{*}{ - Research nurse } & \multirow[t]{5}{*}{ - None } & $\begin{array}{l}\text { - Presentation developed for the } \\
\text { Hispanic culture }\end{array}$ \\
\hline & & & & $\begin{array}{l}\text { - Emphasis on risk factors affecting } \\
\text { the Hispanic community }\end{array}$ \\
\hline & & & & $\begin{array}{l}\text { - Information was not literally translated } \\
\text { to Spanish". }\end{array}$ \\
\hline & & & & $\begin{array}{l}\text { - Verbal/written educational materials in } \\
\text { Spanish about stroke warning } \\
\text { signs/symptoms }\end{array}$ \\
\hline & & & & $\begin{array}{l}\text { - Focus groups with communities to ensure } \\
\text { appropriateness of presentation }\end{array}$ \\
\hline \multirow[t]{2}{*}{6} & \multirow[t]{2}{*}{ Duraski 2007 [50] } & \multirow[t]{2}{*}{ - Research nurse } & \multirow[t]{2}{*}{ - None } & $\begin{array}{l}\text { - Option to have focus groups in Spanish } \\
\text { or English }\end{array}$ \\
\hline & & & & $\begin{array}{l}\text { - Culturally sensitive information, not simply } \\
\text { translated from English to Spanish }\end{array}$ \\
\hline \multirow[t]{2}{*}{7} & \multirow[t]{2}{*}{ Frank 2008 [51] } & Nurse researchers & \multirow[t]{2}{*}{ - None } & \multirow[t]{2}{*}{$\cdot$ No } \\
\hline & & - Nursing students & & \\
\hline 8 & Kalenderian 2009 [53] & Trained ambassadors & - None & $\cdot$ No \\
\hline 9 & Kleindorfer 2008 [54] & $\cdot$ & - None & $\cdot$ No \\
\hline \multirow[t]{2}{*}{10} & \multirow[t]{2}{*}{ Miller 2003 [55] } & \multirow[t]{2}{*}{ - Neuroscience nurses } & - Stages of change & \multirow[t]{2}{*}{$\cdot$ No } \\
\hline & & & - Motivational interviewing & \\
\hline \multirow[t]{5}{*}{11} & \multirow{5}{*}{$\begin{array}{l}\text { Morgenstern } 2007[56] ; \\
\text { Gonzales } 2007 \text { [52]; } \\
\text { Mullen Conley } 2010 \text { [59] }\end{array}$} & - Educator & \multirow[t]{5}{*}{ - Social cognitive theory } & \multirow{2}{*}{$\begin{array}{l}\text { - Culturally sensitive strategy developed } \\
\text { through a focus group with parents, } \\
\text { students and teachers." }\end{array}$} \\
\hline & & - Stroke neurologist & & \\
\hline & & - Data manager & & \\
\hline & & - Science/health teachers & & health professionals in design \\
\hline & & - KIDS project health professionals & & $\begin{array}{l}\text { - Focus groups with local students, parents } \\
\text { and teachers; bilingual materials }\end{array}$ \\
\hline
\end{tabular}


Table 5 Health professionals, theories and cultural adaptation of interventions (Continued)

\begin{tabular}{|c|c|c|c|c|}
\hline \multirow[t]{6}{*}{12} & \multirow[t]{6}{*}{ Villablanca 2009 [57] } & - Site leaders & \multirow[t]{6}{*}{ - Stages of change } & \multirow[t]{6}{*}{$\begin{array}{l}\text { - Culturally appropriate health education } \\
\text { curriculum and materials }\end{array}$} \\
\hline & & - Cardiologists & & \\
\hline & & - Endocrinologists & & \\
\hline & & - Nurses & & \\
\hline & & - Dietitians & & \\
\hline & & $\begin{array}{l}\text { - Physical exercise and other } \\
\text { health professionals" }\end{array}$ & & \\
\hline \multirow[t]{2}{*}{13} & \multirow[t]{2}{*}{ Williams 2008 [58] } & - Two stroke education professionals & \multirow[t]{2}{*}{ • None } & \multirow[t]{2}{*}{ - Rap and hip-hop } \\
\hline & & - 2 community health professionals & & \\
\hline \multirow[t]{2}{*}{14} & \multirow[t]{2}{*}{ Williams 2012 [59] } & $\begin{array}{l}\text { - Children administered the } \\
\text { intervention }\end{array}$ & - Theory of reasoned action & \multirow[t]{2}{*}{ - Rap and hip-hop (songs and dance) } \\
\hline & & & $\begin{array}{l}\text { - Social cognitive theory } \\
\text { (self-efficacy) }\end{array}$ & \\
\hline \multirow[t]{2}{*}{15} & \multirow[t]{2}{*}{ Williamson 2009 [60] } & - Nurses & \multirow[t]{2}{*}{ - None } & \multirow[t]{2}{*}{ • No } \\
\hline & & - Nursing students & & \\
\hline
\end{tabular}

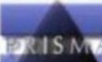

PRISMA 2009 Flow Diagram

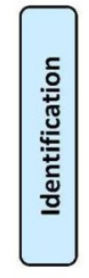

Records identified through database searching $(n=7549)$

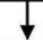

Records after duplicates removed $(n=5737)$

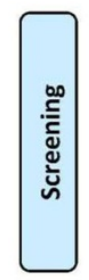

Records excluded as non-English or non-journal articles $(n=602)$
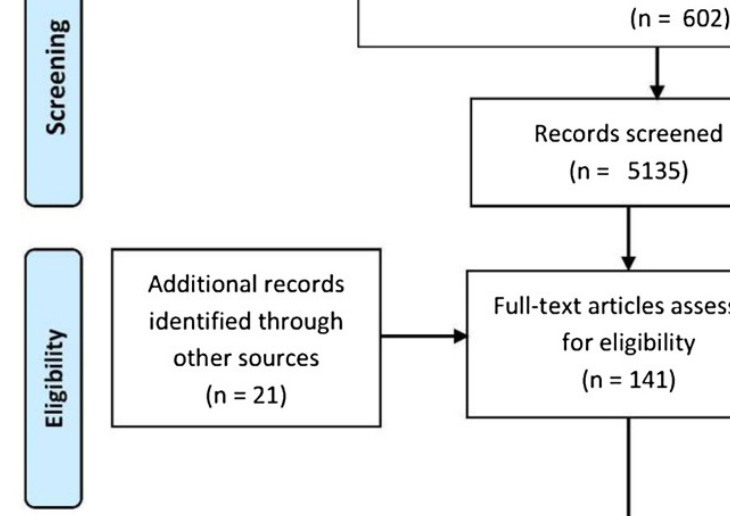

Additional records identified through other sources $(n=21)$
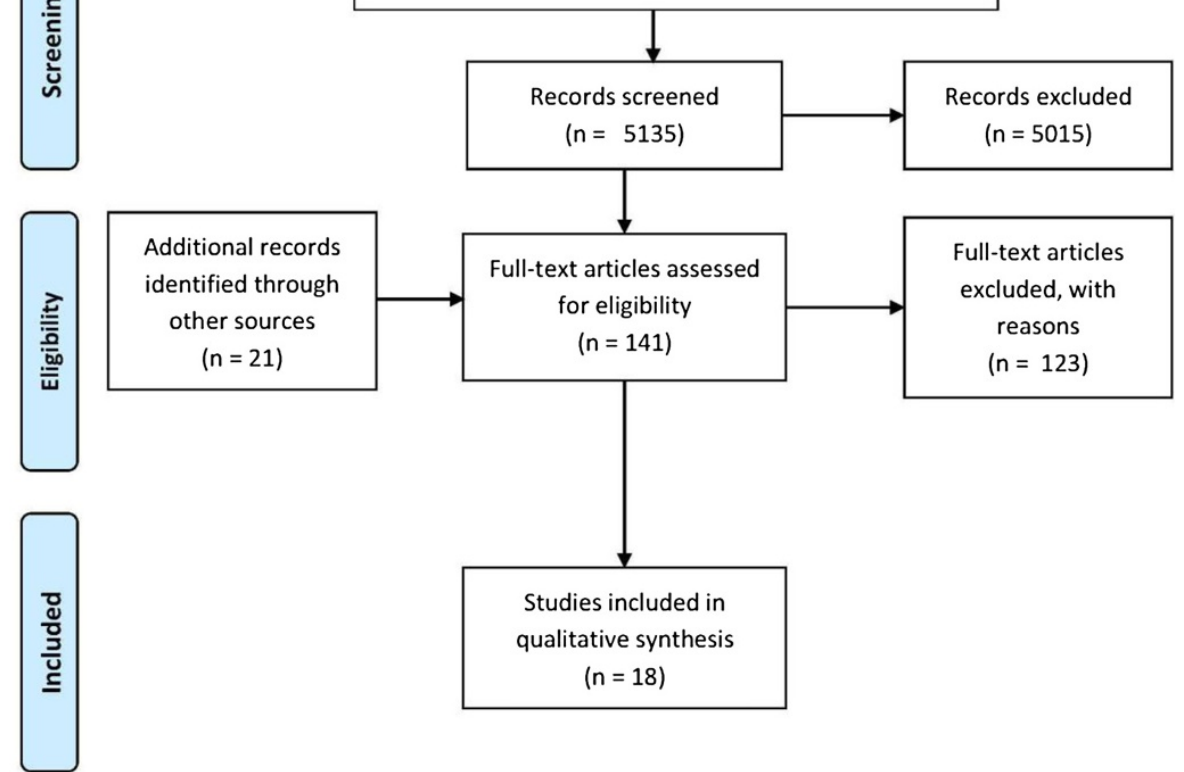

Figure 1 PRISMA 2009 flow diagram representing the selection process. 
available. The first author resolved doubts and interpretive difficulties by discussing specific cases and criteria with all other authors.

To validate the process, two other authors $(\mathrm{AB}$ and EG), blinded and following the same procedures, screened 515 randomly selected references $(10 \%$ of the dataset). Hence, $20 \%$ of the dataset was screened by at least two researchers: the results showed a uniform application of the screening methods. At the end of the screening process, 5015 articles were excluded, according to exclusion and inclusion criteria. Consequently, we thoroughly assessed for eligibility 120 articles, using the abstract and, in case of uncertainty, the full text. For each review identified during the eligibility assessment process, all relevant references were checked and added to the list of articles to be checked for eligibility, if not previously identified by the search strategy. Furthermore, we assessed for eligibility all citations from the included articles that had not been included in the search results. This step allowed for further inclusion of 21 articles. In total, 141 full text articles were assessed for eligibility. Eighteen matched the inclusion and exclusion criteria and were included in the review [29,44-60]. However, in some cases, more than one article reported the results of the same study, referred to different stages of the study. An intervention named "KIDS - Kids identifying and defeating stroke" was reported in three articles $[29,52,56]$. A stroke prevention and awareness intervention for the Hispanic community in the Chicago area was reported in two articles $[48,49]$. "Hip-hop stroke", which was the topic of two articles [58,59], described two entirely distinct phases of the intervention, targeted at different segments of the community and administered by different actors. Hence, they were considered as two different interventions. The total number of interventions found in the literature amounts to 15 studies, reported in 18 articles. Search and selection results also confirmed that no review was available on the topic: consequently, we classified all included articles as primary studies.

\section{Results}

Results of the analysis are described in three synoptic tables, organized according to the P.I.C.O.S. framework, often used in systematic reviews of medical literature $[40,61,62]$. The acronym outlines the five main dimensions of a research question for a systematic review - population, intervention, comparison, outcome and study design. Here, we did not consider comparison, since a number of interventions did not use specific comparators: accordingly, the three tables contain a synoptic description of items referring to population, intervention and outcomes. In the tables, studies are identified by the name of the first author followed by the publication year. The complete reference is available in the final reference list. Two rows contain more than one study, since the results of more than one article were aggregated when they reported on the same intervention.

\section{Specific ethnic minorities, age of subjects and population sizes}

Table 2 displays the main characteristics of the populations targeted by the interventions. Since all interventions took place in the US, African Americans were the most represented ethnic group, targeted by $80 \%$ of interventions, followed by Hispanics (or Mexican Americans), targeted by $53 \%$ of interventions. No other ethnic group was represented.

Most interventions were designed for groups, while 33\% were delivered to individuals. However, such a distinction is sometimes difficult to establish, since in some interventions designed for groups individuals received considerable attention (e.g. by screening, individual counselling after the session, etc.) [e.g. [49,51]. No intervention targeted communities as a whole.

As for the specific population within the target ethnic groups, only $20 \%$ of interventions were targeted at either stroke or TIA patients or patients at risk for stroke. Another $20 \%$ of the interventions were delivered to the general population of a specific geographical area or community, while $60 \%$ were targeted at specific subgroups, such as church members, women, students and parents. Most interventions were targeted at adults (over 18 years of age), with only a few exceptions $[50,56,58]$. Further, population size proved difficult to calculate. To obtain a rough estimate, we classified the intervention as small if it involved less than 100 participants, medium if 101-500 participants were involved, and large in cases of more than 500 participants. According to this criterion, seven interventions were medium, three small and five large. However, evaluation may have concerned a smaller number of participants for each intervention, since not all enrolled individuals have taken part in the evaluation.

\section{Outcomes and study designs}

Table 3 describes the outcomes and study design of included studies.

All interventions aimed at increasing knowledge and behavioural intention, while no intervention was specifically designed to target and measure real behavioural change directed to call EMS when witnessing a stroke.

Sixty-seven per cent of studies had an experimental design and provided some form of evaluation, while $33 \%$ of studies did not provide any evaluation $[46,50,53,57,60]$. However, only a minority of studies (27\%) employed a randomized controlled trial (RCT) design [29,45,47], all the others being case studies. For the evaluation, eight studies used pre- and post-intervention tests 
$[29,45,49,51,54,55,58,59]$, and two were only preliminary reports, lacking evaluation data $[44,47]$.

Of the eight studies providing evaluation results, six were case studies $[49,51,54,55,58,59]$ and two RCTs $[29,45]$. Both case studies and RCTs referred to very different populations, interventions and outcomes. Due to this heterogeneity (as evidenced by the synoptic tables), no quantitative synthesis of results was possible. Two studies reported that the intervention was not effective $[51,55]$. The six studies reporting that the intervention was effective $[45,49,53,56,58,59]$ raise some methodological concerns. Morgenstern et al. [56] found the intervention effective only for a subgroup of the target population (school children), while insufficient data were available to establish the effectiveness of the intervention for the other subgroup (parents). Additionally, the preand post-intervention test was not validated. In two cases, reported in three articles $[45,48,49]$, the difference between pre- and post-intervention test results was minimal, although statistically significant. Finally, Duraski's study [49] had no control group. The lack of a control group also characterizes the other three studies claiming effectiveness for the described interventions [54,58,59]. Evidence of effectiveness exists in all six studies for specific outcomes in specific populations (e.g. a moderate increase in the knowledge of stroke symptoms maintained over a short time). However, no generalizable evidence of effectiveness exists for health promotion interventions aimed at improving knowledge of stroke symptoms and related actions in BME communities. All included studies used only quantitative methodology to evaluate the effectiveness of interventions, thus excluding both qualitative and mixed methods designs.

\section{Interventions: country, focus and delivery techniques}

Tables 4 and 5 summarize the most important dimensions of the health promotion interventions described in the selected articles.

Firstly, all interventions were carried out in the United States. Consequently, all data concern a specific context, and no data on other relevant areas such as Europe, the Far East or Australia is available. All interventions included at least a component relating to awareness of stroke symptoms and related actions. Forty percent were mostly focussed on awareness, 33\% had a shared focus between awareness and prevention or risk factors, while $27 \%$ were focussed on prevention or risk factors, with only few activities on awareness of symptoms. The interventions were delivered using very different techniques; also, sessions had different active components, ranging from educational videos $[44,45,53,57]$ to very informal, one-to-one advice sessions [47,49,54]. Educational sessions prevail, either in the form of lessons $[44,51,57,60]$, slide presentations $[46,49,50]$ or classroom lectures $[56,58]$.
Often, such sessions were interactive, allowing for the exchange of questions and answers between health promoters and the audience, and occasional role playing $[44,49,50,54,58]$. Five interventions also included distribution of informative materials about stroke, and in some interventions these materials were meant to be shared with families and friends $[46,53,54,56,59]$. For further details, see Table 3, column "intervention type".

\section{Duration of interventions, settings and actors involved}

Interventions administered in a single session of information and advice were generally brief, lasting between 30 minutes and two hours. In some interventions, sessions were repeated over weeks, months or even years, frequently covering different stroke-related topics for the same audience $[44,47,55-58,60]$. Interventions were delivered in a range of different settings. Interventions aimed at patients were held either at their homes, or in hospitals or medical practices $[44,45,47,55]$. Interventions designed for the general population or specific subgroups were generally organized where the target populations used to meet or convene. Hence, churches were used for church members $[46,51,53,57,60]$, schools for students [56,58], community centres and organizations $[46,49]$, hospitals and medical practices [53] and one intervention was held in abeauty salon [54].

Actors designing and delivering the interventions varied widely. Forty-seven percent of interventions were delivered by multiprofessional groups, while $53 \%$ were delivered by a single profession. Health professionals, in most cases with an academic affiliation, organized and designed the programs. Interventions were delivered by nurses, research nurses and nursing students [44,49-51,55,57,60], trained health champions or ambassadors (students, church members, beauticians) $[46,47,53,54,59]$, health educators and other community health workers $[44,47,58]$, physicians [56,57].

\section{Theories underpinning interventions and techniques for cultural adaptation}

We explored the extent to which the interventions were theory-based, and whether they provided clear definitions of cultural adaptation. Fifty-three percent of studies $[45,49-51,53,54,58,60]$ did not mention the utilization of any theory to design and evaluate the intervention. As for the remaining studies it is difficult to define them as theory-based, since theories were only briefly mentioned, and no clear link with the factual content of the health promotion program was established. Four studies $[44,46,56,58]$ mentioned social cognitive theory [63], three $[44,47,55]$ motivational interviewing [64], three more $[46,55,57]$ stages of change [65], two $[47,58]$ theory of reasoned action see also [66,67], one [47] theory of planned behaviour [68]. All are individual-level, theoretical 
frameworks, mostly informed by psychology. Further, in most cases theories were used as a reference for stroke risk and prevention, and only in three instances $[44,56,59]$ for the component of the intervention addressing stroke symptoms and related actions.

As for cultural adaptation of interventions, as many as $33 \%$ of the studies did not mention any specific strategy; two further studies $[46,47]$ simply referred generically to cultural tailoring or cultural sensitivity of the interventions. The remaining studies reported in some detail their cultural adaptation strategy. These included different tactics and practical actions. Four programs $[44,49,50,56]$ adopted of languages spoken by ethnic minorities for materials and events (especially for Hispanic communities), or used a language corresponding to the level of health literacy of community members. Three interventions $[44,49,56]$ incorporated the point of view and specific issues of communities through focus groups or committees of community actors or workers in planning and implementation, early feedback, or community involvement. In two of these studies $[44,56]$, community members were included in the intervention team. A related strategy was to include community-based role models as actors, artists or testimonials, and to use visuals integrating community places or surroundings $[44,45,56,58,59]$. Moreover, two studies [44,49] reported addressing community-specific barriers to behaviour change, and specific health beliefs and risk factors. Some consideration was also given to the social structure of communities, with related roles and cultural characteristics. "Familism", family structures and intergenerational contact were taken into account [56] and dance and hip-hop were used to convey the health promotion message [58,59].

None of these studies referred to general frameworks or models of cultural adaptation, theories of ethnicity, and the like, the approach being mostly practical. Consequently, no common definition of cultural competence or adaptation emerged from the included studies. Moreover, no study included a specific justification of the reason why some specific cultural traits had been selected as typical of that particular community.

\section{Barriers and facilitators for the success of interventions}

No study aimed at systematically identifying barriers and facilitators for the success of the interventions, hence comments on such a topic were occasional. Only the importance of funding and continuity of the program over time was identified as a facilitator in $27 \%$ of the studies $[46,51,57,60]$. Other facilitators included the involvement of gatekeepers of the venues where the interventions took place $[51,54,60]$, providing transportation $[44,47,48]$ and financial incentives or gifts [29] and using reminders to increase participation [52]. Moreover, using small groups in interventions [51], combining a "captive audience" and a trusted educator [54] and giving participants individual attention [51] seemed to facilitate participation in some of the interventions. Conversely, barriers included time demands on gatekeepers, health professionals and coordinators [57] and the young age of some prospective participants, not perceiving stroke prevention as a priority [29].

\section{Community involvement: strategies and problems}

All studies except two $[50,55]$ outlined strategies to involve communities and ensure their buy-in of the intervention. Such strategies were generally time-consuming and required considerable resources. Examples included the use of committees of advocates, gatekeepers and community members, to obtain advice on community involvement, program content and delivery techniques and channels and on the final evaluation. Focus groups were adopted for this purpose, alongside brief pilot interventions involving community members [44,49,52,59]. Particular care was taken in identifying community gatekeepers to help or take the lead in organizing sessions $[48,51,54,57,60]$, while some interventions explicitly adopted a train-the trainer approach $[46,47,53,54,57,60]$. In this case, health professionals and campaigners provided stroke education to specific members of the community, such as school children, pastors, beauticians, who, in turn, played a relevant part in educating parents, customers or church attendants. In the case of a particularly sizeable and structured program, the whole organization of sessions in a community site (association, church, etc.) was devolved to previously instructed local leaders [57]. Other involvement strategies included fostering flexibility and community creativity [52,57], using community-based health professionals [29,57], and adopting multi-channel involvement strategies (word of mouth, gatekeepers, web site, advertising, community association meetings) $[29,57]$.

No intervention was aimed at specific social networks within communities. When sizeable groups were targeted, the main objective was still to increase the knowledge of individuals within the groups, without consideration for community or social network dynamics. Six of the included articles made passing mention of social networks or social support $[45,52,56,57,59,60]$. Some studies mentioned the importance of using schoolchildren as trainers for their parents, regarding stroke knowledge, and underlined the related difficulties [56,59]. Others generically mentioned the importance of improving stroke knowledge of relatives and other members of the support networks for stroke patients [45,52]. The most complex intervention stressed both the importance and the difficulty of coordinating networks of different organizations involved [57]. In the same study social ties and networks were used to recruit participants for the intervention, and to plan, test and implement it. Collaboration between networked 
actors with different roles was highlighted as important for the success of a further intervention [60]. However, none of the interventions put in place a systematic strategy for tapping social networks and social support resources.

\section{Educational strategies adopted in the interventions}

Ten studies emphasized the value of active, interactive and experiential education strategies, but only some of these provided details of the educational methods. Small groups [29,57], role-plays and enactment of scenarios by participants [29,44,59], encouraging flexible discussion of stroke awareness [29,44,56-58], enabling self-efficacy $[29,52,56]$ and interactive multimedia resources $[29,52,56,58]$ were the most frequently cited methods. Exercises and assignments were used to promote involvement of participants in producing health promotion materials and spreading the message to their families $[29,52,56,57,59]$. Arts and music were also employed to involve community members in the educational activities, together with promoting the creativity of participants $[29,52,56,58,59]$. In long interventions [29,52,56-60], different methods were linked to each other and produced positive feedback. For example, in one circumstance, students interviewed their parents on stroke awareness and then produced information materials accordingly $[29,56]$.

\section{Discussion}

Community-based health promotion (CBHP) interventions are usually considered complex and difficult to plan, perform, and evaluate. This is due to the high number of variables involved, including complex behavioural factors, the influence of culture and norms on health behaviours and the simultaneous presence of several health promotion interventions [69,70].

This difficulty is clearly revealed by the studies included in our review. Firstly, even in a relatively homogeneous context of community-based health promotion interventions aimed at African Americans or Hispanics living in the US, planning and evaluation methods differed significantly. There is growing recognition that the design and evaluation of health promotion interventions need to be informed by theory [71-73]. However, theory-based health promotion interventions were in the minority in the sample used for our review. Consequently, clearly specifying the theoretical foundations of the design and evaluation methods of an intervention may considerably improve its implementation.

Moreover, theories used in the included studies focussed on the individual level, while six studies have recently showed that community- and network-level theories may prove effective in designing and evaluating community-based health promotion interventions [74-79]. Hence, using community- or network-oriented theories may help health promoters to systematically take into account dimensions of an intervention that could have a significant impact on its effectiveness.

Furthermore, no evidence was available for European countries, where minorities show cultural and social characteristics directly influencing health-related attitudes differing from US minorities. For example, Scheppers et al. [80] show that ethnic minorities experience a number of barriers to accessing health services, frequently linked with particular cultural, religious or social practices. Such practices are different between ethnic minorities: for example, UK Pakistanis and US African-Americans are likely to have very different health beliefs and ill healthattribution. Scheppers et al. also maintain [80], that the organization of health services in different countries plays an important contextual role in shaping health-related attitudes of ethnic minorities. Also, studies concerning the definition of cultural competence often emphasize the importance of specific, contextual aspects, rather than abstract definitions of ethnicity, in order to successfully conduct health promotion and health care initiatives [38,81]. Therefore, specific key factors (perception of health and illness, language, available community resources, specific barriers and facilitators) may greatly differ between different ethnic minorities living in different countries. For all these reasons, it seems difficult to generalize any results from the included studies to the UK or European situation. It would, however, be important to note that further research related to stroke awareness improvement is aimed at addressing non-US based ethnic minorities.

Although in most studies cultural adaptation was considered as important, cultural adaptation was almost always linked to practical or pragmatic strategies. Consequently, no intervention took into account the recent contributions that tried to define cultural appropriateness of interventions and the main principles for conducting research on ethnicity and health [37-39]. Consequently, using theory and data from this specific literature may help in designing interventions that are more congruent with specific characteristics of ethnic minorities.

Furthermore, the evidence of effectiveness emerging from the included studies is inconclusive. Fifty-three percent of the studies provided evaluation results, and only $25 \%$ of these included a control group. As a result, current available evidence of the effectiveness of such interventions seems inconclusive. In addition, no qualitative study satisfied our inclusion criteria. While acknowledging the importance of quantitative evidence, it seems that integrating a qualitative approach would be appropriate for complex health promotion interventions. In fact, such interventions involve different variables such as ethnicity, knowledge and behaviour change, 
and - most importantly - their success seems to heavily depend on complex contextual factors. Qualitative research is often advocated as an appropriate method in evaluating health promotion interventions $[82,83]$ especially because it can provide an holistic perspective [84,85]. Qualitative research may therefore explore this under-researched topic and identify dimensions influencing the effectiveness of stroke awareness interventions for ethnic minorities.

\section{Strengths and limitations}

To the best of our knowledge, this was the first systematic review to date on health promotion interventions for stroke awareness in ethnic minorities. The results outline the main characteristics of stroke awareness interventions for ethnic minorities in the US, alongside strength and limitations of both the interventions and the evaluation procedures. Review findings may therefore provide a useful starting point for academics and practitioners wishing to further analyse or plan similar health promotion initiatives in other parts of the world.

Limitations include the fact that searches were restricted to peer-reviewed journal literature written in the English language. Although we searched the most relevant databases, broadening the search to supplementary sources and including more languages may increase the number of retrieved studies. The same results might be obtained by the inclusion of conference proceedings, dissertations, books and book chapters and grey literature results.

\section{Implications for further research}

Since cultural adaptation seems important in this context, there is a critical need for studies on health promotion interventions for stroke awareness in ethnic minorities other than African Americans and Hispanics.

Furthermore, such interventions operate in very complex scenarios, and several variables may have an impact on their effectiveness. Qualitative or mixed-methods study designs may help to understand contextual factors influencing community-based health promotion, including barriers and facilitators, experiential education strategies and methods for involving communities.

Finally, network- and community-level health promotion theories may contribute useful insights both in designing and evaluating health promotion interventions on stroke awareness for ethnic minorities.

\section{Conclusions}

In this review we set out to find evidence about the effectiveness of interventions to increase stroke awareness in ethnic minorities. Our results show that this is a particularly understudied area, and that all included studies refer to the US.
Evidence of effectiveness from 11 case reports and four RCTs focussed on short- to medium-term knowledge improvement for individuals seems particularly weak and inconclusive. Therefore, we suggest that further research is conducted on different countries and ethnic minorities.

\section{Endnote}

${ }^{\text {a }}$ The acronym of the campaign stands for Face, Arms, Speech, Time to call EMS (the first three being distinctive stroke symptoms).

\section{Competing interests}

The authors declare that they have no competing interests.

\section{Authors' contributions}

All authors contributed equally in designing the study and critically discussing the results. PG carried out the bibliographic searches, selected the studies, analysed the data, contributed to the discussion and drafted the manuscript. EG and TR contributed to the study design, selection of studies and interpreting the results. $A B$ contributed to design the search strategies, the selection process and the interpretation of results. EG, TR and $A B$ critically revised the manuscript. All authors read and approved the final manuscript.

\section{Acknowledgements}

The author's PhD was funded through a CLAHRC studentship as part of the Stroke Theme programme of the National Institute of Health Research (NIHR) CLAHRC for South Yorkshire. All views and opinions expressed are those of the author, and not necessarily those of the NHS, the NIHR or the Department of Health. Further details of the CLAHRC for South Yorkshire and the Stroke Theme can be found at www.clahrc-sy.nihr.ac.uk.

\section{Author details}

${ }^{1}$ School of Health and Related Research, University of Sheffield, Regent Court, 30 Regent Street, Sheffield S1 4DA, UK. ${ }^{2}$ School of Nursing and Midwifery, The University of Sheffield, Barber House, 387 Glossop Road, Sheffield S10 $2 \mathrm{HQ}$, UK.

Received: 26 May 2013 Accepted: 14 April 2014

Published: 28 April 2014

\section{References}

1. The top 10 Causes of Death; [http://www.who.int/mediacentre/factsheets/ fs310/en/index.html]

2. World Health Organization: The Global Burden of Disease: 2004 Update. Geneva, Switzerland: World Health Organization; 2008.

3. Donnan GA, Fisher M, Macleod M, Davis SM: Stroke. Lancet 2008, 371:1612-1623.

4. Go AS, Mozaffarian D, Roger VL, Benjamin EJ, Berry JD, Borden WB, Bravata DM, Dai S, Ford ES, Fox CS, Franco S, Fullerton HJ, Gillespie C, Hailpern SM, Heit JA, Howard VJ, Huffman MD, Kissela BM, Kittner SJ, Lackland DT, Lichtman JH, Lisabeth LD, Magid D, Marcus GM, Marelli A, Matchar DB, McGuire DK, Mohler ER, Moy CS, Mussolino ME, et al: Heart disease and stroke statistics-2013 update. A report from the American heart association. Circulation 2013, 127:e6-e245.

5. Centers for Disease Control and Prevention: Prevalence and most common causes of disability among adults-United States, 2005. MMWR Morb Mortal Wkly Rep 2009, 58:421-426.

6. Moon L, Moise P, Jacobzone S, ARD-Stroke Experts Group: A Comparison of Treatment, Costs and Outcomes in 17 Countries. Paris: OECD; 2003.

7. Demaerschalk BM, Hwang H-M, Leung G: US cost burden of ischemic stroke: a systematic literature review. Am J Manag Care 2010, 16:525-533.

8. Liebson PR: Cardiovascular disease in special populations III: stroke. Prev Cardiol 2010, 13:1-7

9. Trimble BM: Stroke in minorities. Neurol Clin 2008, 26:1177-1190. xi. 
10. Gunarathne A, Patel JV, Gammon B, Gill PS, Hughes EA, Lip GYH: Ischemic stroke in South Asians: a review of the epidemiology, pathophysiology, and ethnicity-related clinical features. Stroke 2009, 40:e415-e423.

11. Heuschmann PU, Grieve AP, Toschke AM, Rudd AG, Wolfe CDA: Ethnic group disparities in 10-year trends in stroke incidence and vascular risk factors The South London Stroke Register (SLSR). Stroke 2008, 39:2204-2210.

12. National Institute for Health and Clinical Excellence: Alteplase for the Treatment of Acute Ischaemic Stroke. London: National Institute for Health and Clinical Excellence; 2007

13. Reeves MJ, Arora S, Broderick JP, Frankel M, Heinrich JP, Hickenbottom S, Karp H, LaBresh KA, Malarcher A, Mensah G, Moomaw CJ, Schwamm L, Weiss P: Acute stroke care in the US: results from 4 pilot prototypes of the Paul Coverdell national acute stroke registry. Stroke 2005, 36:1232-1240.

14. Fonarow GC, Smith EE, Saver JL, Reeves MJ, Bhatt DL, Grau-Sepulveda MV, Olson DM, Hernandez AF, Peterson ED, Schwamm LH: Timeliness of tissue-type plasminogen activator therapy in acute ischemic stroke. Clinical perspective patient characteristics, hospital factors, and outcomes associated with door-to-needle times within 60 minutes. Circulation 2011, 123:750-758.

15. Kleindorfer D, Khoury J, Broderick JP, Rademacher E, Woo D, Flaherty ML, Alwell K, Moomaw CJ, Schneider A, Pancioli A, Miller R, Kissela BM: Temporal trends in public awareness of stroke: warning signs, risk factors, and treatment. Stroke 2009, 40:2502-2506.

16. Teuschl Y, Brainin M: Stroke education: discrepancies among factors influencing prehospital delay and stroke knowledge. Int J Stroke 2010, 5:187-208.

17. Addo J, Ayis S, Leon J, Rudd AG, McKevitt C, Wolfe CD: Delay in presentation after an acute stroke in a multiethnic population in South london: the South london stroke register. J Am Heart Assoc 2012, 1:e001685.

18. Seshadri S, Beiser A, Kelly-Hayes M, Kase CS, Au R, Kannel WB, Wolf PA: The lifetime risk of stroke: estimates from the Framingham study. Stroke 2006, 37:345-350

19. Jones SP, Jenkinson AJ, Leathley MJ, Watkins CL: Stroke knowledge and awareness: an integrative review of the evidence. Age Ageing 2010, 39:11-22.

20. Department of Health: National Stroke Strategy. London: Department of Health Publications; 2007

21. Royal College of Physicians: Intercollegiate Stroke Working Party: National Clinical Guideline For Stroke. 4th edition. London: Royal College of Physicians; 2012.

22. Haute Autorité de Santé: Stroke: Early Management (Alert, Prehospital Phase, Initial Hospital Phase, Indications for Thrombolysis). Guidelines; 2009.

23. National Stroke Foundation (Australia): Clinical Guidelines for Stroke Managemen. Melbourne: National Stroke Foundation; 2010.

24. Moreira E, Correia M, Magalhães R, Silva MC: Stroke awareness in urban and rural populations from Northern Portugal: knowledge and action are independent. Neuroepidemiology 2011 36:265-273.

25. Willey JZ, Williams O, Boden-Albala B: Stroke literacy in central Harlem: a high-risk stroke population. Neurology 2009, 73:1950-1956.

26. Lecouturier J, Murtagh MJ, Thomson RG, Ford GA, White M, Eccles M, Rodgers $\mathrm{H}$ : Response to symptoms of stroke in the UK: a systematic review. BMC Health Serv Res 2010, 10:157.

27. Lecouturier J, Rodgers H, Murtagh M, White M, Ford G, Thomson R: Systematic review of mass media interventions designed to improve public recognition of stroke symptoms, emergency response and early treatment. BMC Public Health 2010, 10:784.

28. Moloczij N, McPherson KM, Smith JF, Kayes NM: Help-seeking at the time of stroke: stroke survivors' perspectives on their decisions. Health SoC Care Community 2008, 16:501-510.

29. Mullen Conley K, Juhl Majersik J, Gonzales NR, Maddox KE, Pary JK, Brown DL, Moyé LA, Espinosa N, Grotta JC, Morgenstern LB: Kids Identifying and Defeating Stroke (KIDS): development and implementation of a multiethnic health education intervention to increase stroke awareness among middle school students and their parents. Health Promot Pract 2010, 11:95-103

30. Wein TH, Staub L, Felberg R, Hickenbottom SL, Chan W, Grotta JC, Demchuk AM, Groff J, Bartholomew LK, Morgenstern LB: Activation of emergency medical services for acute stroke in a nonurban population: the T.L.L. Temple Foundation Stroke Project. Stroke 2000, 31:1925-1928.

31. Skolarus LE, Zimmerman MA, Murphy J, Brown DL, Kerber KA, Bailey S, Fowlkes S, Morgenstern LB: Community-based participatory research: a new approach to engaging community members to rapidly call 911 for stroke. Stroke 2011, 42:1862-1866.

32. Morren JA, Salgado ED: Stroke literacy, behavior, and proficiency in a South Florida population. J Stroke Cerebrovasc Dis 2012, 22:962-968.

33. Stroke - Act F.A.S.T. [http://www.nhs.uk/actfast/Pages/stroke.aspx]

34. Bietzk E, Davies R, Floyd A, Lindsay A, Greenstone H, Symonds A, Greenfield S: FAST enough? The U.K. general public's understanding of stroke. Clin Med 2012, 12:410-415.

35. Robinson TG, Reid A, Haunton VJ, Wilson A, Naylor AR: The face arm speech test: does it encourage rapid recognition of important stroke warning symptoms? Emerg Med J 2013, 30:467-471.

36. Department of Health: Progress in Improving Stroke Care. London: The Stationery Office; National Audit Office; 2010.

37. Beach MC, Price EG, Gary TL, Robinson KA, Gozu A, Palacio A, Smarth C, Jenckes MW, Feuerstein C, Bass EB, Powe NR, Cooper LA: Cultural competence: a systematic review of health care provider educational interventions. Med Care 2005, 43:356-373.

38. Netto G, Bhopal R, Lederle N, Khatoon J, Jackson A: How can health promotion interventions be adapted for minority ethnic communities? Five principles for guiding the development of behavioural interventions. Health Promot Int 2010, 25:248-257.

39. Mir G, Salway S, Kai J, Karlsen S, Bhopal R, Ellison GT, Sheikh A: Principles for research on ethnicity and health: the Leeds consensus statement. Eur J Public Health 2013, 23(3):504-510.

40. Moher D, Liberati A, Tetzlaff J, Altman DG: Preferred reporting items for systematic reviews and meta-analyses: the PRISMA statement. J Clin Epidemiol 2009, 62:1006-1012.

41. The National Institute of Neurological Disorders and Stroke rt-PA Stroke Study Group: Tissue plasminogen activator for acute ischemic stroke. N Engl J Med 1995, 333:1581-1587.

42. Cooper HM: Synthesizing research: a guide for literature reviews. Thousand Oaks, Cali: SAGE; 1998.

43. Braun V, Clarke V: Using thematic analysis in psychology. Qual Res Psychol 2006, 3:77-101.

44. Boden-Albala B, Stillman J, Perez T, Evensen L, Moats H, Wright C, Moon-Howard J, Doyle M, Paik MC: A stroke preparedness RCT in a multi-ethnic cohort: design and methods. Contemp Clin Trials 2010, 31:235-241.

45. Chan Y-F, Lavery R, Fox N, Kwon R, Zinzuwadia S, Massone R, Livingston D: Effect of an educational video on emergency department patient stroke knowledge. J Emerg Med 2008, 34:215-220.

46. Covington CF, King JA, Fennell I, Jones C, Hutchinson C, Evans A: Developing a community-based stroke prevention intervention course in minority communities: the DC Angels Project. J Neurosci Nurs 2010, 42:139-142.

47. Dromerick AW, Gibbons MC, Edwards DF, Farr DE, Giannetti ML, Sánchez B, Shara NM, Fokar A, Jayam-Trouth A, Ovbiagele B, Kidwell CS: Preventing recurrence of thromboembolic events through coordinated treatment in the District of Columbia. Int J Stroke 2011, 6:454-460.

48. Duraski SA: Meeting the needs of the community: a project to prevent stroke in Hispanics. Top Stroke Rehabil 2003, 9:46-56.

49. Duraski SA: Stroke prevention education in the Hispanic community Rehabil Nurs 2006, 31:5-9.

50. Duraski SA: Do Hispanic children need to know about stroke prevention? Top Stroke Rehabil 2007, 14:65-71.

51. Frank D, Grubbs L: A faith-based screening/education program for diabetes, CVD, and stroke in rural African Americans. ABNF J 2008, 19:96-101.

52. Gonzales NR, Brown DL, Maddox KE, Conley KM, Espinosa N, Pary JK, Karim AP, Moyé LA, Grotta JC, Morgenstern LB: Kids Identifying and Defeating Stroke (KIDS): design of a school-based intervention to improve stroke awareness. Ethn Dis 2007, 17:320-326.

53. Kalenderian E, Pegus C, Francis C, Goodwin N, Jacques HS, Lasa D: Cardiovascular disease urban intervention: baseline activities and findings. J Community Health 2009, 34:282-287.

54. Kleindorfer D, Miller R, Sailor-Smith S, Moomaw CJ, Khoury J, Frankel M: The challenges of community-based research: the beauty shop stroke education project. Stroke 2008, 39:2331-2335. 
55. Miller ET, Spilker J: Readiness to change and brief educational interventions: successful strategies to reduce stroke risk. J Neurosci Nurs 2003, 35:215-222.

56. Morgenstern LB, Gonzales NR, Maddox KE, Brown DL, Karim AP, Espinosa N, Moye LA, Pary JK, Grotta JC, Lisabeth LD, Conley KM: A randomized, controlled trial to teach middle school children to recognize stroke and call 911: the kids identifying and defeating stroke project. Stroke 2007 38:2972-2978.

57. Villablanca AC, Arline S, Lewis J, Raju S, Sanders S, Carrow S: Outcomes of national community organization cardiovascular prevention programs for high-risk women. J Cardiovasc Trans/ Res 2009, 2:306-320.

58. Williams O, Noble JM: "Hip-Hop" stroke: a stroke educational program for elementary school children living in a high-risk community. Stroke 2008, 39:2809-2816.

59. Williams O, DeSorbo A, Noble J, Gerin W: Child-mediated stroke communication: findings from Hip Hop stroke. Stroke 2012, 43:163-169.

60. Williamson W, Kautz DD: "Let's get moving: let's get praising:" promoting health and hope in an African American church. ABNF J 2009, 20:102-105.

61. Armstrong EC: The well-built clinical question: the key to finding the best evidence efficiently. WMJ 1999, 98:25-28.

62. University of York: Nhs Centre For Reviews And Dissemination, Systematic reviews: CRD's guidance for undertaking reviews in health care. York: CRD, University of York; 2009.

63. Bandura A: Social Foundations of Thought and Action: A Social Cognitive Theory. Englewood Cliffs, N.J.: Prentice-Hall; 1986.

64. Miller WR, Rollnick S: Motivational Interviewing: Preparing People For Change. New York: Guilford Press; 2002.

65. Prochaska JO, DiClemente CC: Stages and processes of self-change of smoking: toward an integrative model of change. J Consult Clin Psychol 1983, 51:390-395.

66. Fishbein M: A theory of reasoned action: some applications and implications. Nebr Symp Motiv 1980, 27:65-116.

67. Fishbein M: An integrative model for behavioral prediction and its application to health promotion. In Emerging Theories in Health Promotion Practice and Research. San Francisco: Jossey-Bass; 2009:215-234.

68. Ajzen I: The theory of planned behavior. Organ Behav Hum Decis Process 1991, 50:179-211.

69. Victora CG, Habicht J-P, Bryce J: Evidence-based public health: moving beyond randomized trials. Am J Public Health 2004, 94:400-405.

70. Thorogood M, Coombes Y: Evaluating Health Promotion: Practice and Methods. Oxford; New York: Oxford University Press; 2010.

71. DeBarr KA: A review of current health education theories. Calif $J$ Health Promot 2004, 2:74-87.

72. Rimer BK, Glanz K: Theory at a Glance: A Guide For Health Promotion Practice. Bethesda, MD: National Cancer Institute; 2005.

73. Abraham C, Michie S: A taxonomy of behavior change techniques used in interventions. Health Psychol 2008, 27:379-387.

74. Valente TW: Social Networks and Health: Models, Methods, and Applications. Oxford; New York: Oxford University Press; 2010.

75. Valente TW: Network interventions. Science 2012, 337:49-53.

76. Luke DA, Harris JK: Network analysis in public health: history, methods, and applications. Annu Rev Public Health 2007, 28:69-93.

77. Gilchrist A: The Well-Connected Community: A Networking Approach To Community Development. Bristol: Policy Press; 2004.

78. Wendel ML, Burdine JN, McLeroy KR, Alaniz A, Norton B, Feliz MRJ: Community capacity: theory and application. In Emerging Theories in Health Promotion Practice and Research. San Francisco: Jossey-Bass: 2009:277-302.

79. Bryant CA, McCormack Brown KR, McDermott RJ, Debate RD, Alfonso ML, Baldwin JA, Monaghan P, Phillips LM: Community-based prevention marketing: a new framework for health promotion interventions. In Emerging Theories in Health Promotion Practice and Research. San Francisco: Jossey-Bass; 2009:331-356.

80. Scheppers E, Dongen van E, Dekker J, Geertzen J, Dekker J: Potential barriers to the use of health services among ethnic minorities: a review. Fam Pract 2006, 23:325-348.

81. Williamson $M$, Harrison L: Providing culturally appropriate care: a literature review. Int J Nurs Stud 2010, 47:761-769.

82. Naidoo J, Wills J: Foundations for Health Promotion. Edinburgh: Elsevier; 2009
83. Hubley J, Copeman J: Practical Health Promotion. Polity: Cambridge, UK; 2008.

84. Tremblay M-C, Richard L: Complexity: a potential paradigm for a health promotion discipline. Health Promot Int 2011. doi:10.1093/heapro/dar054 First published online: September 8, 2011.

85. Matheson A, Dew K, Cumming J: Complexity, evaluation and the effectiveness of community-based interventions to reduce health inequalities. Health Promot J Austr 2009, 20:221-226.

doi:10.1186/1471-2458-14-409

Cite this article as: Gardois et al:: Health promotion interventions for increasing stroke awareness in ethnic minorities: a systematic review of the literature. BMC Public Health 2014 14:409.

\section{Submit your next manuscript to BioMed Central and take full advantage of:}

- Convenient online submission

- Thorough peer review

- No space constraints or color figure charges

- Immediate publication on acceptance

- Inclusion in PubMed, CAS, Scopus and Google Scholar

- Research which is freely available for redistribution

Submit your manuscript at www.biomedcentral.com/submit
C) BioMed Central 